\title{
The Architecture and Biological Function of Dual Antibody-Coated Dendrimers: Enhanced Control of Circulating Tumor cells and Their Hetero-Adhesion to Endothelial Cells for Metastasis Prevention
}

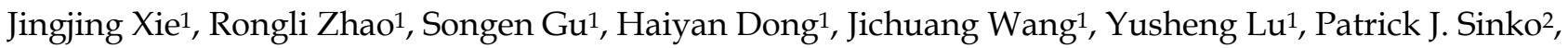 \\ Ting $\mathrm{Yu}^{1}$, Fangwei $\mathrm{Xie}^{3}$, Lie Wang ${ }^{3}$, Jingwei Shao ${ }^{1,4}{ }^{\bowtie}$, Lee Jia ${ }^{1,4}$ \\ 1. Cancer Metastasis Alert and Prevention Center, College of Chemistry, Fuzhou University, Fuzhou 350002, China. \\ 2. Rutgers, The State University of New Jersey, 160 Frelinghuysen Road, Piscataway, NJ, 08854, USA. \\ 3. Department of Medicine Oncology, East Hospital of Xiamen University, Fuzhou 350004, China. \\ 4. Biopharmaceutical photocatalysis, State Key Laboratory of Photocatalysis on Energy and Environment, Fuzhou University, Fuzhou 350002, \\ China.
}

$\square$ Corresponding author: Lee Jia (cmapcjia1234@163.com or pharmlink@gmail.com) or Jingwei Shao (shaojingwei@fzu.edu.cn), 523 Industry Road, Science Building, 3FL., Fuzhou University, Fuzhou, Fujian, China, 350002. Phone and Fax: +86-0591-8357-6912.

( ) Ivyspring International Publisher. This is an open-access article distributed under the terms of the Creative Commons License (http://creativecommons.org/ licenses/by-nc-nd/3.0/). Reproduction is permitted for personal, noncommercial use, provided that the article is in whole, unmodified, and properly cited.

Received: 2014.02.07; Accepted: 2014.06.17; Published: 2014.09.26

\begin{abstract}
Dissemination of circulating tumor cells (CTCs) in blood and their hetero-adhesion to vascular endothelial bed of distant metastatic secondary organs are the critical steps to initiate cancer metastasis. The rarity of CTCs made their in vivo capture technically challenging. Current techniques by virtue of nanostructured scaffolds monovalently conjugated with a single antibody and/or drug seem less efficient and specific in capturing CTCs. Here, we report a novel platform developed to re-engineer nanoscale dendrimers for capturing CTCs in blood and interfering their adhesion to vascular endothelial bed to form micrometastatic foci. The nanoscale dendrimers were spatiotemporally accommodated with dual antibodies to target two surface biomarkers of colorectal CTCs. Physiochemical characterization, including spectra, fluorescence, electron microscope, dynamic light scattering, electrophoresis, and chromatography analyses, was conducted to demonstrate the successful conjugation of dual antibodies to dendrimer surface. The dual antibody conjugates were able to specifically recognize and bind CTCs, moderately down-regulate the activity of the captured CTCs by arresting them in $\mathrm{S}$ phase. The related adhesion assay displayed that the dual antibody conjugates interfered the hetero-adhesion of CTCs to fibronectin (Fn)-coated substrates and human umbilical vein endothelial cells (HUVECs). The dual antibody conjugates also showed the enhanced specificity and efficiency in vitro and in vivo in restraining CTCs in comparison with their single antibody counterparts. The present study showed a novel means to effectively prevent cancer metastatic initiation by binding, restraining CTCs and inhibiting their hetero-adhesion to blood vessels, not by traditional cytotoxic-killing of cancer cells.
\end{abstract}

Key words: Cancer metastasis; Circulating tumor cells; PAMAM dendrimers; Dual antibody conjugation; Cell binding and regulation; Cell adhesion.

\section{Introduction}

Cancer recurrence after surgical removal of primary tumor means the dissemination, seeding and engraftment of malignant carcinoma cells in sites to distant metastatic tissues. The serious cancer metastasis is the root cause of cancer death [1-3]. Dissemination of circulating cancer cells (CTCs) in blood and 
their adhesion to local vascular endothelium are the critical starting points of cancer metastasis $[4,5]$. CTCs are cancer cells in peripheral blood derived from primary tumors with the clonal capability to diffuse, adhere to vascular endothelium, and invade extravascularly to distant organs $[6,7]$. The dormant CTCs in remission could survive with cancer patients as long as for ten to twenty years [8,9]. Once CTCs are activated, cancer metastasis can be initiated by such a subpopulation of activated CTCs in blood [10]. The increased number of CTCs closely correlates with the aggressive cancers and decreased time to relapse [11].

Current cancer therapy focuses on the traditional chemotherapeutics which mainly targets the high-proliferative cancer cells, not the dormant CTCs in blood (the high potential for metastasis). The low efficiency of the post-metastatic chemotherapy wasn't able to effectively and specifically inhibit or reverse the cancer metastasis regardless of the immune impairment, multidrug resistance, and adverse effects caused by the cytotoxic or targeted chemotherapeutives.

Nanotechnology-based medicines with high sensitivity and accuracy made it possible to realize the real-time and dynamic detection and diagnosis of solid tumor [12, 13]. However, the current tumor-targeting nanoparticles are delimited to the improved cytotoxic effects of chemotherapeutic drugs, not the enhanced capture efficiency for the rare CTCs in blood circulation. Besides, only a few nanomaterials were developed to interfere the adhesion of tumor cells to endothelial cells. Thus, design of nanomedicines to interfere the cancer metastasis by targeting the adhesion of CTCs to vascular endothelial cells will be a new strategy for preventing cancer metastasis [14].

Effective cancer metastasis prevention requires safe and effective nanotechnology-based products that can recognize CTCs and down-regulate their activities [12]. Owing to the extreme rarity of CTCs in abundant hematologic cells (roughly $1 / 10^{3}-10^{6}$ ) [15-18], the recognition and capturing of CTCs are technically challenging. To solve the technical hurdles, a series of platforms, such as immunofluorescence labeling using antibodies against biomarkers on CTC surface [16, 19], microfluidic devices monovalently modified with targeting ligands [20-23], or nanostructured substrates coated with anti-EpCAM (aEpCAM) or aptamers [24-28], were developed. However, those techniques are focused on sensitive in vitro detection for diagnosis only, and the techniques by virtue of a single CTCs biomarker are not efficient and specific enough for capturing CTCs. Considering that one type of human CTCs usually simultaneously expresses more than one surface biomarker [29], and the abundance of one biomarker varies dynamically with the cell cycle of the investigated cells [30,31], we therefore hypothesized that a single antibody conjugate bind to a single specific surface antigen on the rare CTCs, whereas multiple diversified antibody conjugates can simultaneously recognize and bind more biomarkers of a cell phenotype with greater binding avidity, allowing the multiple diversified antibody conjugates to distinguish cell type (CTC vs. normal cells), tumor type (benign vs. malignant status), metastatic potential (epithelial CTC vs. mesenchymal CTC), and proliferation capability. Moreover, multiple antibodies coated on the same nanomaterial could simultaneously bind to their individual specific biomarkers of a single CTC. The tight binding could lead to the restraint of the CTCs.

To test the hypothesis and realize the greater capturing and down-regulation of CTCs, we selected human colorectal carcinoma HT29 cell as a CTC model, and targeted the two CTCs biomarkers, i.e., the epithelial cell adhesion molecule (EpCAM) [32, 33] and the saliva acidifying louis oligosaccharides $X$ (Slex) [29,34], and coated the corresponding antibodies (aEpCAM and aSlex) to the surface of the G6 PAMAM dendrimers. Following the biological architecture and physiochemical characterization of the single and dual antibody-coated dendrimers, we demonstrated the enhanced capture efficacy of the dual antibody-coated conjugates in vitro and in vivo. Since the hetero-adhesion of the CTCs to the vascular endothelial cells is viewed by us the initial starting point of cancer metastatic cascade [4], we also investigated if the dual antibody conjugates could interfere the hetero-adhesion of the human CTCs to the human endothelial cells. The study was reported here.

\section{Materials and Methods}

\section{I Materials}

PAMAM dendrimers (generation 6, theoretical MW 624,00 Da, ethylenediamine core) were purchased from Shandong Weihai Chenyuan New Silicone Materials, Co. Ltd. Succinic anhydride (SA), Deuterium Oxide (99.9 atom \% $\left.\mathrm{D}, \mathrm{D}_{2} \mathrm{O}\right)$, 1-ethyl-3-(3-dimethylaminopropyl) carbodiimide hydrochloride (EDC.HCL), and N-hydroxysuccinimide (NHS) were obtained from Aladdin Reagent Co., Ltd. Bovine serum albumin (fraction V, BSA) and purified human EpCAM antibody (aEpCAM, MW150 KDa) were purchased from Sigma-Aldrich and Abcam (Hong Kong) Ltd., respectively. Anti-human CD15s (aSlex, MW150 KDa), fluorescein isothiocyanate (FITC) linked aSlex (aSlex-FITC) and phycoerythrin (PE) linked aEpCAM (aEpCAM-PE) were provided by BD company. FITC Annexin V Apoptosis Detection Kit I and PI/RNase Staining Buffer used for flow 
cytometry analysis were provided by BD company. Dyes including iodide [3,3'-Dihexyloxacarbocyanine iodide] (DiOC6(3)), dihydrochloride (DAPI), acridine orange and ethidium bromide (AO/EB), Hoechst 33258, Rhodamine $123 \quad(\geq 85 \%$ (HPLC)), and [3-(4,5-dimethylthiazol-2-yl)-2,5-diphenyltetrasodium bromide] tetrazolium salt (MTT) were purchased from Sigma-Aldrich. All other chemicals, unless otherwise specified, were all purchased from Sinopharm Chemical Reagent Co., Ltd and used without further purification.

\subsection{Chemical re-engineering of G6 PAMAM dendrimers with fluorescence or non-fluorescence labeled antibodies}

G6 PAMAM dendrimers were firstly modified with SA to prepare the partially and completely carboxylated G6 PAMAM (PC G6 and CC G6) dendrimers [24]. PC G6 dendrimers were conjugated with FITC by reacting the remaining amine group $\left(-\mathrm{NH}_{2}\right)$ of PC G6 with the sulfur cyanide group $(\mathrm{S}=\mathrm{C}=\mathrm{N}-)$ of FITC, and successively conjugated with antibody by using the carboxylic ends. CC G6 dendrimers were directly conjugated with antibody or fluorescence-labeled antibody. Briefly, $80 \mathrm{mg}$ G6- $\left(\mathrm{NH}_{2}\right)_{256}$ $(1.28 \mu \mathrm{mol})$ was dissolved in $2 \mathrm{~mL}$ DMSO, and reacted with $32.8 \mathrm{mg}$ SA (328 $\mu \mathrm{mol}, 1: 1$ molar ratio) for PC G6 dendrimers (G6-COOH). G6- $\left(\mathrm{NH}_{2}\right)_{256}(60 \mathrm{mg})$ was mixed with $246 \mathrm{mg}$ SA $(660 \mu \mathrm{mol}, 10$-fold molar excess over G6) in $2 \mathrm{~mL}$ DMSO for CC G6 dendrimers $\left(\mathrm{G} 6-(\mathrm{COOH})_{256}\right)$. All the reactions were conducted under vigorous stirring overnight. For FITC linked dendrimers (G6-COOH-FITC), 24 mg PC G6 dendrimers were reacted with $1.4 \mathrm{mg}$ FITC (5-fold molar excess over PC G6) in $2 \mathrm{~mL}$ DMSO, and $0.168 \mathrm{~g} \mathrm{Na}-$ $\mathrm{HCO}_{3}$ was added to make the remaining amine ends $\left(-\mathrm{NH}_{2}\right)$ of dendrimer easy to be covalently coupled with sulfur cyanide group $(\mathrm{N}=\mathrm{C}=\mathrm{S}-)$ of FITC under the $\mathrm{pH}$ value of 9.5. The reaction was conducted in dark for two days. All the resulting G6 PAMAM derivatives were dialyzed against DDI water to remove the unreacted molecules as well as organic solvent, and obtained as powder by lyophilization.

Single or dual antibody-coated dendrimers were synthesized by employing the EDC catalytic method [24]. The synthesized conjugates without fluorescence labeling were designated as G6-5A, G6-5S and G6-5A-5S based on the reaction molar ratios of CC G6 to each antibody aEpCAM (A) or/and aSlex (S). Briefly, the CC G6 dendrimers $(0.83 \mu \mathrm{g}, 11.86 \mathrm{pmol})$ dissolved in $3 \mathrm{~mL}$ phosphate-buffered saline (PBS) buffers after activation with EDC (113.66 ng, 592.90 pmol, 50-fold molar excess over CC G6) and NHS (68.24 ng, 592.90 pmol, 50-fold molar excess over CC G6) at room temperature for $1 \mathrm{~h}$ were divided into three vials. Each was reacted with aEpCAM at 19.75 pmol (5-fold molar excess over CC G6) for G6-5A conjugate, aSlex at 19.75 pmol (5-fold molar excess over CC G6) for G6-5S conjugate, and the combined aEpCAM (19.75 pmol) and aSlex (19.75 pmol) for G6-5A-5S conjugate. Fluorescence-labeled single or dual antibody conjugates G6-5A-PE, G6-5S-FITC and PE-5A-G6-5S-FITC were similarly synthesized and designated using aEpCAM-PE (A-PE, orange fluorescence) and aSlex-FITC (S-FITC, green fluorescence), instead. All the reactions were under vigorous stirring overnight in dark. Finally, the resultant conjugates were purified via dialysis $(10,000 \mathrm{MWCO}$, Thermo scientific, Rockford, IL) against DDI water overnight to remove the small molecules and followed by lyophilization.

\subsection{Physiochemical characterization and biostability of dendrimer-antibody conjugates}

Chemical structures of dendrimer derivatives and dendrimer-antibody conjugates were confirmed by ${ }^{1} \mathrm{HNMR}$ (an AVANCE III 500MHz NMR system, Bruker, Switzerland) in $\mathrm{D}_{2} \mathrm{O}$ and FTIR (a Nicolet 360 Fourier Transform IR spectrometer, Nicolet Instruments, Inc.). Surface morphology and particle size were determined both by field emission scanning electron microscope (FSEM, Nova Nano SEM 230) and atomic force microscope (AFM, Agilent AFM 500, tapping probe $40 \mathrm{~N} / \mathrm{m}$, and AC mode) images. Distribution of zeta potential $(\mathrm{mV})$ and hydrodynamic diameter (nm) in aqueous solution was measured by a Zeta potential/ dynamic light scattering analyzer (Zetaplus/90plus, BIC, Brookharen). The number of FITC molecules in each PC G6 dendrimer and the amount of antibody in each single antibody conjugate was respectively estimated according to the fluorescence intensity at $\lambda_{\mathrm{ex}} 492 \mathrm{~nm}, \lambda_{\mathrm{em}} 530 \mathrm{~nm}$ (F-4600 Fluorescence spectrophotometer, Hitachi LTD., Japan) and UV absorption value at $\lambda 220 \mathrm{~nm}$ (Quawell 5000 UV-Vis Spectrophotometer, America). The presence of antibody or fluorescence-labeled antibody on dendrimer surface was confirmed using SDS-PAGE gradient electrophoresis (Life technologies) and laser confocal microscope analysis (Olympus FluoView 1000). The difference in molecular weights of modified and functionalized dendrimers was determined by using a reversed phase high performance liquid chromatogram (HPLC) system (Hitachi, Japan) consisting of a solvent module, a UV detector and a Yarra $3 \mu \mathrm{m}$ SEC 4000 column $(300 \times 7.8 \mathrm{~mm})$.

The stability of conjugates was evaluated by UV spectra analysis. Conjugates were measured at different $\mathrm{pH}(5.6,7.4,9.13), \mathrm{T}^{\circ} \mathrm{C}\left(4,37^{\circ} \mathrm{C}\right)$, vibration rate $(80,120,210 \mathrm{rpm})$ and incubation time $(0,0.5,1,2,4,8$, $16,24,48,36 \mathrm{~h})$. 


\subsection{Cell culture}

Human umbilical vein endothelial cells (HUVECs) were obtained clinically as described by this laboratory [35,36]. After incubation with $1 \mathrm{mg} / \mathrm{mL}$ of collagenase for $15 \mathrm{~min}$ at $37{ }^{\circ} \mathrm{C}$, HUVECs were cultured with M199 medium supplemented with 20\% fetal bovine serum (FBS), $100 \mu \mathrm{g} / \mathrm{mL}$ endothelial cell growth supplement (ECGS), $50 \mu \mathrm{g} / \mathrm{mL}$ heparin sodium and $1 \%$ penicillin/ streptomycin $(\mathrm{P} / \mathrm{S})$ in a $0.2 \%$ gelatin-coated culture flask. Human cell lines including normal non-carcinoma embryonic lung fibroblast cells HELF, melanoma cells A-375, cervical cancer cells Hela and hepatocellular carcinoma cells HepG2 were obtained from our in-house frozen cell stock cryopreserved in ampoules in a large repository and maintained in RPMI 1640 medium supplemented with $10 \%$ heat-inactivated fetal calf serum (FCS), 1\% $\mathrm{P} / \mathrm{S}$ except that human colorectal carcinoma cells HT29 were purchased from the Type Culture Collection of the Chinese Academy of Sciences, Shanghai, China and maintained in McCoy's 5a medium supplemented with $10 \%$ FBS and $1 \% \mathrm{P} / \mathrm{S}$. All the cell lines above were grown in a humidified atmosphere of $5 \%$ $\mathrm{CO}_{2}$ at $37{ }^{\circ} \mathrm{C}$ in the final confluence of $70-80 \%$ for subsequent experiments.

\subsection{Flow cytometry procedures}

Flow cytometric analysis was carried out on a Becton Dickinson FACS Aria III cell sorter with laser excitation set at $488 \mathrm{~nm}$. Fluorescence signals derived from PI or PE were detected through $585 \mathrm{~nm}$ bandpass filters. Fluorescence signals derived from DiOC6(3) or FITC were detected through $530 \mathrm{~nm}$ bandpass filters. Gating strategy was used to set P1 gate for selecting the target HT29 cells according to the forward versus side scatter histograms. Side angle scattered light (SSC) versus PI or DiOC6(3) histogram was set to analyze the changes in cell cycle and mitochondrial membrane potential (MMP) of HT29 after affected by the conjugates. For analysis of apoptosis in HT29 cells, compensation was made for FITC and PI dyes followed by dot plots to show the percentage of cell population within each plot quadrant, which revealed the distribution of cells in every stage (debris, viable, apoptotic and necrotic). Finally, data acquisition was collected based on 10,000 cells to meet the light scatter criteria. Initial data analysis was performed using the BD FACS Diva software provided with the system.

\subsection{Fluorescent observation of capturing the adherent and suspensory cells by the conjugates}

Fluorescence-labeled single or dual antibody conjugates were used to observe the binding and capture between the conjugates and HT29 in vitro. The procedures were performed imitating human microenvironment. For the adherent cells, laser confocal microscope (Olympus FluoView 1000) analysis was performed. Cells cultivated on $35 \mathrm{~mm}$ dishes with glass coverslips in the bottom were pretreated with PBS containing 1\% BSA (1\% PBSA) for $30 \mathrm{~min}$ to exclude the non-specific binding. After incubation with fluorescence-labeled single or dual antibody conjugates (G6-5A-PE, G6-5S-FITC and PE-5A-G6-5S-FITC) at the concentration of $20 \mu \mathrm{g} / \mathrm{mL}$ for $1 \mathrm{~h}$ at $37{ }^{\circ} \mathrm{C}$ in a humidified atmosphere of $5 \% \mathrm{CO}_{2}$, cells were washed and stained with PBS buffer containing the nuclei stain DAPI $(10 \mu \mathrm{g} / \mathrm{mL})$ for $15 \mathrm{~min}$. Finally, cells were covered with serum-free medium for images at FITC $\lambda_{\text {ex }} 488 \mathrm{~nm}, \lambda_{\text {em }} 500-535 \mathrm{~nm}$ and PE $\lambda_{\text {ex }} 550 \mathrm{~nm}, \lambda_{\text {em }}$ $570-610 \mathrm{~nm}$, respectively. For the suspensory cells, fluorescence inverted microscope (Axio Observer A1, Zeiss, Germany) analysis was conducted. Cells $\left(10^{6}\right)$ in each tube were pre-labeled with Hoechst 33258 (blue color) for $15 \mathrm{~min}$ to demonstrate the presence of cell nucleus, and treated with fluorescence-labeled antibody (A-PE, S-FITC) or single antibody conjugates (G6-5A-PE, G6-5S-FITC) for $1 \mathrm{~h}$ at $37^{\circ} \mathrm{C}$ water bath in dark after being sealed up with 1\% PBSA for $30 \mathrm{~min}$. After removal of the unbound conjugates, cells were suspended in $100 \mu \mathrm{L}$ PBS for images at $\lambda_{\text {ex }} 470 / 40 \mathrm{~nm}$, $\lambda_{\text {em }} 525 / 50 \mathrm{~nm}$.

\subsection{Viability analysis of cells captured by the conjugates}

The cell viability, cell cycle distribution, cell apoptosis and cellular MMP were analyzed by the methods developed and validated by the laboratory [37-39].

Anti-proliferation efficacy: The MTT assay was performed. Human cell lines including HELF, A-375, Hela, HepG2 and HT29 were cultivated on the 96-well plates at the final density of $5 \times 10^{4}-10^{5}$ cells/ $\mathrm{mL}$ based on the different cell characteristics and growth ability. Cell lines in the final confluence of $70 \%-80 \%$ were individually incubated with varying concentrations of G6-5A-5S conjugate. To study whether the synthesized single or dual antibody conjugates could down-regulate the HT29 cell activity, the cells were individually treated with single or dual antibody conjugates (G6-5A, G6-5S and G6-5A-5S) at concentrations ranging from 1.25 to $20 \mu \mathrm{g} / \mathrm{mL}$. After $48 \mathrm{~h}$ of incubation, $100 \mu \mathrm{L}$ of serum-free medium containing 1 $\mathrm{mg} / \mathrm{mL}$ MTT solution was added to each well for another $4 \mathrm{~h}$ to allow MTT to be metabolized to formazan. A solution of $0.04 \mathrm{~N} \mathrm{HCl}$ in isopropyl alcohol was then added to stop the MTT reaction. Finally, the supernatant was aspirated and $150 \mu \mathrm{L}$ of DMSO was added to each well to dissolve the water-insoluble 
blue formazan. The cell viability was determined by the absorption values at a wavelength of $570 \mathrm{~nm}$ read on a Tecan Infinite M200 pro multifunctional microplate reader.

Cell cycle distribution: To explore how the conjugates affected the viability of captured cells, flow cytometry was used to analyze the cell cycle distribution. HT29 cells cultivated on the 6-well plates were exposure to single or dual antibody conjugates (G6-5A, G6-5S and G6-5A-5S) at various concentrations $(0,10,20 \mu \mathrm{g} / \mathrm{mL})$ for $48 \mathrm{~h}$. Cells were trypsinised and washed with ice-cold PBS for three times. After centrifugation at $200 \mathrm{~g}, 6 \mathrm{~min}$, cells at the density of $1 \times 10^{6}$ in each tube were fixed with $1 \mathrm{~mL}$ of $70 \%$ ice-cold ethanol at $-20{ }^{\circ} \mathrm{C}$ overnight. Fixed cells were washed and suspended again with PBS, PI staining experiment was performed at $37^{\circ} \mathrm{C}$ following the kit instructions. Data acquisition and analysis were obtained on a BD FACS Aria III flow cytometer and DNA integration software MFLT32, respectively. The blockage of cell cycle was finally determined based on the percentiles of cell population in every phase (G0/G1, S and G2/M) between the treated and control groups.

Apoptotic analysis: Fluorescence microscope and flow cytometric analyses were used to further evaluate the apoptotic influences of single or dual antibody conjugates on the captured cells. Briefly, HT29 cells were cultivated on the 6-well plates and individually incubated with G6-5A, G6-5S and G6-5A-5S conjugates $(0,10,20 \mu \mathrm{g} / \mathrm{mL})$ for $48 \mathrm{~h}$ followed by three times of washing with PBS, and harvested by centrifugation. One kind of treatment was that $25 \mu \mathrm{L}$ cell suspension at the density of $1 \times 10^{6} / \mathrm{mL}$ was stained with $1 \mu \mathrm{L}$ mixed dyes AO/EB in dark for 15-30 min, then a fluorescence inverted microscope (Zeiss Axio Observer A1) was used to take the images at $\lambda_{\text {ex }} 510 \mathrm{~nm}$. Another was that Annexin V-FITC apoptosis detection kit was applied to determine the apoptotic and necrotic states of HT29 cells after treatment. Annexin V-FITC $(5 \mu \mathrm{L})$, PI $(5 \mu \mathrm{L})$ and binding buffer $(500 \mu \mathrm{L})$ were mixed and added to each well, then kept in dark for 15 min. Cells in different stages were analyzed within $1 \mathrm{~h}$ by flow cytometry (BD FACS Aria III).

Cellular MMP measurement: The change in cellular MMP accounts for the degree of apoptosis. MMP in HT29 cells was measured using DiOC6(3) (a lipotropy cationic fluorescent dye). HT29 cells cultured in the confluence of $70-80 \%$ were incubated with single or dual antibody conjugates $(0,10,20 \mu \mathrm{g} / \mathrm{mL})$ for $48 \mathrm{~h}$. After trypsinised and collected, cells were treated with $500 \mu \mathrm{L}$ of $2 \mathrm{nM}$ DiOC6(3) working solution at 37 ${ }^{\circ} \mathrm{C}$ for $20 \mathrm{~min}$. Finally, the fluorescence intensity of the cells was examined by the flow cytometry and the change in cellular MMP was expressed as the $\triangle \psi \mathrm{m}$ of the treated cells versus the untreated control.

\subsection{Inhibition of the captured cells adhered to endothelial cells}

The capability of single or dual antibody conjugates to inhibit the adhesion of HT29 cells to fibronectin (Fn)-coated substrates and HUVECs was respectively investigated.

Substrate adhesion assay: First of all, $10 \mathrm{ng} / \mathrm{mL}$ Fn was coated on the substrates of 96-well plate overnight, then discarded and sealed up with $2 \%$ PBSA for $30 \mathrm{~min}$. Cell suspension containing G6-5A, G6-5S and G6-5A-5S conjugates at various concentrations $(0,1.25,2.5,5,10 \mu \mathrm{g} / \mathrm{mL})$ was individually incubated on the wells for $1 \mathrm{~h}$. The post-processing was similar to what was described in MTT assay. 100- $\mu \mathrm{L}$ serum-free medium containing $1 \mathrm{mg} / \mathrm{mL}$ MTT solution was used for another $4 \mathrm{~h}$. After the supernatant was aspirated, $100 \mu \mathrm{L}$ of DMSO was added to each well to dissolve the water-insoluble blue formazan. Finally, the optical density was read on a Tecan Infinite M200 pro multifunctional microplate reader at a wavelength of $570 \mathrm{~nm}$ to determine their respective anti-adhesion ability to Fn-coated substrates. The adhesion rate was calculated by dividing $A_{570 \mathrm{~nm}}$ of the treated group by that of the control.

HUVECs adhesion assay: HUVECs were cultivated on the 24-well plate in the confluence of $90 \%$, and treated with $1 \mathrm{ng} / \mathrm{mL}$ IL-1 $\beta$ for $4 \mathrm{~h}$ to up-regulate expression of cell adhesion molecules (CAMs), followed by co-incubation of the HUVECs with the mixture of Rhodamine 123-labeled colon cancer cells HT29 and the conjugates at concentrations ranging from 1.25 to $10 \mu \mathrm{g} / \mathrm{mL}$ for $1 \mathrm{~h}$. After removal of the non-adhered cells by washing them with PBS, ten visual fields were randomly selected and taken images by a fluorescence inverted microscope (Axio Observer A1, Zeiss, Germany) at $\lambda_{\mathrm{ex}} 470 / 40 \mathrm{~nm}, \lambda_{\mathrm{em}}$ $525 / 50 \mathrm{~nm}$. The capability of conjugates to inhibit HT29 cells to HUVECs was quantitatively determined by the numbers of fluorescence-labeled cells that adhered to HUVECs in samples relative to those in the control group.

\subsection{In vivo capture experiment}

The mice used in these investigations were handled in accordance with the Guide for the Care and Use of Laboratory Animals (National Research Council, 1996) to minimize the animals' suffering and to reduce the number of animals used. Human HT29 cells at the density of $5 \times 10^{4}$ were intravenously injected to the $\mathrm{nu} / \mathrm{nu}$ mice (weighing $20 \mathrm{~g}, \mathrm{n}=2$ ). $10 \mathrm{~min}$ later, $200 \mu \mathrm{L}$ of $400 \mu \mathrm{g} / \mathrm{mL}$ fluorescence-labeled single or dual antibody conjugates (G6-5A-PE, G6-5S-FITC 
and PE-5A-G6-5S-FITC) were individually injected to each mouse by tail vein. The mice injected with the equal volume of PBS were used as the negative control. By $1 \mathrm{~h}$ after the injection, $1 \mathrm{~mL}$ of blood was extracted from the heart and collected into EDTA tubes. RBCs were lysed, and the isolated cells (HT29 cells and WBCs) were blocked with 1\% BSA at room temperature for $30 \mathrm{~min}$, then incubated with APC-conjugated anti-CD 45 at $37^{\circ} \mathrm{C}$ in a water bath for another $30 \mathrm{~min}$ to label the WBCs. All the residual cells were stained with DAPI $(50 \mu \mathrm{g} / \mathrm{mL})$ for $15 \mathrm{~min}$ in dark. Finally, cells were analyzed by the flow cytometry to determine the numbers of HT29 cells captured by the single or dual antibody conjugates and the corresponding capture efficiency.

\section{I 0 Statistical analysis}

Every experiment was performed independently and repeated at least three times. CC G6 was tested as the negative control in each individual experiment. Data were presented as the means \pm standard deviations (SD). Statistical analysis was done by Student's t-test and one-way analysis of variance (One-ANOVA). Multiple comparisons of the means were made through One-ANOVA analysis and demonstrated by the least significance difference (LSD) test (IBM SPSS Statistics 19.0). The symbol of * and ${ }^{* *}$ represented the comparison between sample and control, while \# and \#\# represented the comparison between any two samples. A probability value $<0.05$ was considered statistically different $\left({ }^{*}\right.$ and $\left.{ }^{*}\right)$, and $<0.01$, significantly different $(* *$ and $\# \#)$.

\section{Results and discussion}

\section{I Synthesis and characterization of single or dual antibody conjugates}

Dendrimers with minor modification were spatiotemporally accommodated with fluorescence or non-fluorescence labeled antibodies by employing the EDC/NHS conjugation chemistry as shown in Fig. 1a. The physiochemical characterization of conjugates was conducted using UV, AFM, FSEM, dynamic light scattering (DLS), HPLC, electrophoresis and fluorescent measurements to show the difference before and after modification and conjugation of the dendrimers. Though the CC G6 dendrimers had their intrinsic ultraviolet absorption values at $\lambda 210 \mathrm{~nm}$ and autofluorescence (blue) at $\lambda_{\mathrm{ex}} 250 \mathrm{~nm}, \lambda_{\mathrm{em}} 276 \mathrm{~nm}$ and $300 \mathrm{~nm}$ $[40,41]$, the absorption didn't affect the observation of antibody or fluorescence-labeled antibody on dendrimer surface. The UV values at $\lambda 220 \mathrm{~nm}$ and merged fluorescence (yellow-green color) at $\lambda_{\text {ex }} 488$ and $543 \mathrm{~nm}$, respectively, demonstrated the conjugation of antibodies and fluorescence-labeled antibodies to dendrimers (Fig. 1b). Characteristic ultraviolet absorption peaks at $\lambda 220 \mathrm{~nm}$ enabled approximately 2 aEpCAM in G6-5A conjugate and 6 aSlex in G6-5S conjugate according to the corresponding standard curves of aEpCAM and aSlex. The SDS-PAGE electrophoregram showed a distinct protein band at MW $50 \mathrm{kDa}$, probably representing the heavy chain of the antibody aEpCAM dissociated from the dual antibody conjugates when the latter was reduced and heated at $70{ }^{\circ} \mathrm{C}$ for $10 \mathrm{~min}$ before the SDS-PAGE protein analysis. HPLC analysis confirmed the increased molecular weight with the amounts of antibody on dendrimer surface increased. AFM and FSEM images displayed G6-5A-5S conjugate was approximately 1 $\mathrm{nm}$ high and $100 \mathrm{~nm}$ wide with the morphology of round pie (Fig. 1c, d). DLS measurements also showed the increased hydrodynamic diameter and negative zeta potential after the dendrimers were coated with dual antibodies (Supplementary Material: Table S1). However, the hydrodynamic diameter seemed to be larger than its actual diameter, probably because of the aggregation characteristics of G6-5A-5S conjugate. The spatial and high payload advantages of PAMAM dendrimers facilitated the multivalent conjugation with dual antibodies. The successful coating process made the dual antibody-coated dendrimers available for further biological tests, including capture, down-regulation of HT29 cells, and further inhibition of their adhesion to endothelial cells (Fig. 1e).

\subsection{Biostability of conjugates}

UV spectra at $\lambda 220 \mathrm{~nm}$ showed that conjugates were relatively stable in PBS solution $(\mathrm{pH} 7.4)$ for at least $12 \mathrm{~h}$ at $37^{\circ} \mathrm{C}$, and two weeks at $4{ }^{\circ} \mathrm{C}$. The stability of the conjugates seemed not to be affected by shaking at velocity $210 \mathrm{rpm}$ (Supplementary Material: Fig. S1a-c). However, acid and alkaline $\mathrm{pH}$ might lead the antibodies on dendrimer surface to be denatured and dissociated (Supplementary Material: Fig. S1d).

\subsection{Enhanced cell binding and capture}

The capacity of binding and capturing HT29 cells by the single or dual antibody conjugates was qualitatively analyzed by fluorescence measurement. For the adherent cells, a laser confocal microscope was used. After $1 \mathrm{~h}$ of incubation with fluorescence-labeled single or dual antibody conjugates, the cells showed the distinct merged colors pink, turquoise and blue-green-yellow in cellular membrane components, which respectively indicated their binding to G6-5A-PE, G6-5S-FITC and PE-5A-G6-5S-FITC conjugates (Fig. 2a). For the suspensory cells, Hoechst 33258 (blue color) was used to show the integrity of cell nucleus. aEpCAM or 
aSlex-coated dendrimers showed the specific capture of the HT29 cells. The captured cells displayed orange or green color on the cytomembrane imaged by a fluorescence inverted microscope. Compared with A-PE and S-FITC antibody alone, single antibody conjugates G6-5A-PE and G6-5S-FITC captured more target cells (Fig. 2b). a
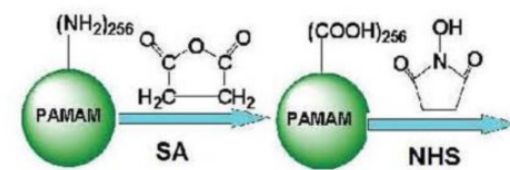

b

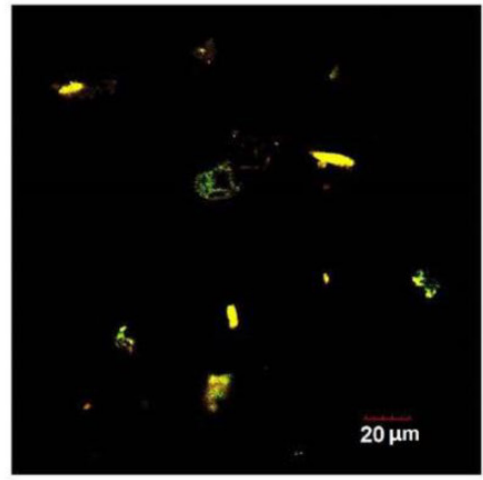

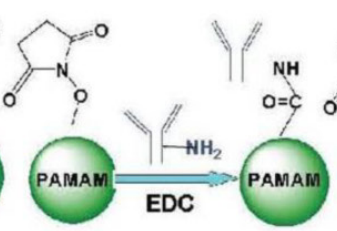

C

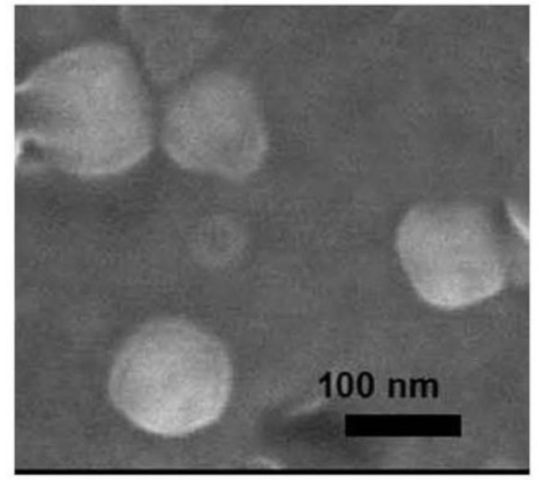

d
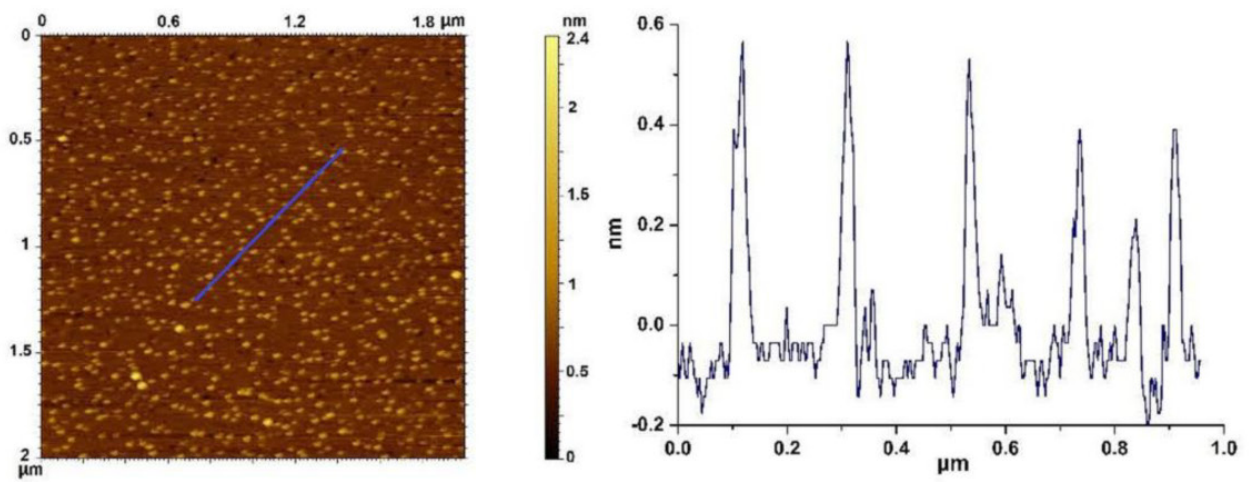

e



Figure I. Synthesis and physiochemical characterization of dual antibody-coated dendrimers for their application in cancer metastatic prevention. a, Schematic view of the conjugation between the surface-modified dendrimers and antibody (aEpCAM or/and aSlex). b, A fluorescent image of PE-5A-G6-5S-FITC conjugate taken by a laser confocal microscope at FITC $\lambda_{\text {ex }} 488 \mathrm{~nm}, \lambda_{\mathrm{em}} 500-535 \mathrm{~nm}$ and PE $\lambda_{\mathrm{ex}} 568 \mathrm{~nm}, \lambda_{\mathrm{em}} 560-660 \mathrm{~nm}$. c, FSEM image of the dual antibody conjugate G6-5A-5S. d, A typical AFM image of single antibody conjugate G6-5S. e, Schematic illustration of how the dual antibody-coated dendrimer conjugates bind the adherent and suspensory colon cancer cells, down-regulate the cell activity and further inhibit their adhesion to endothelial cells. 

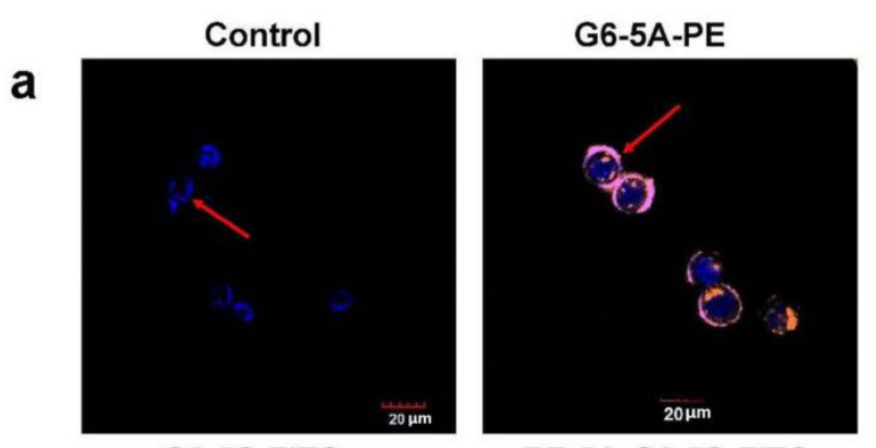

PE-5A-G6-5S-FITC
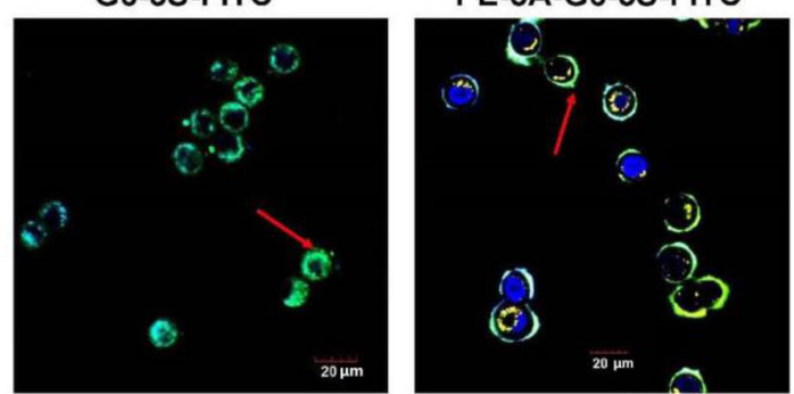

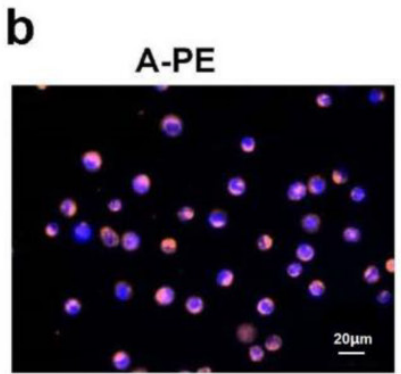

S-FITC

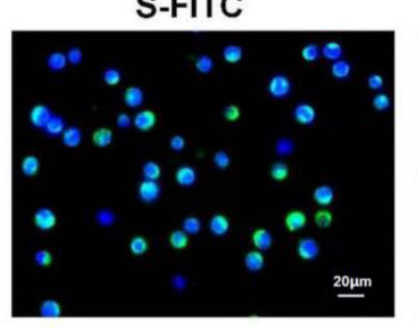

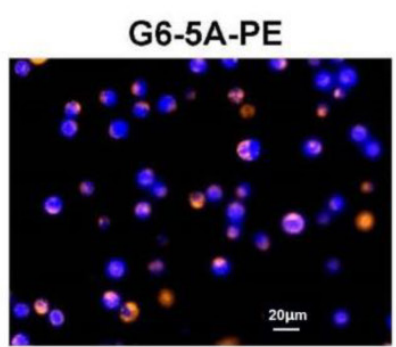

G6-5S-FITC

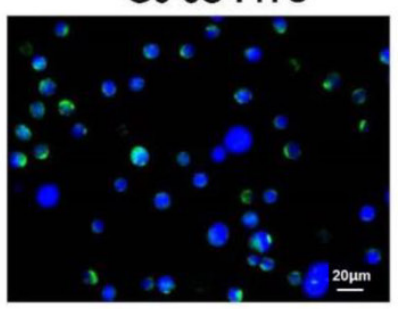

Figure 2. Images of the bound or captured HT29 cells by the fluorescence-labeled single or dual antibody conjugates. a, The adherent HT29 cells showed distinct colors once recognized and bound by the conjugates. $\mathbf{b}$, The suspensory cells were more captured by the conjugates than their antibody counterparts. Blue color indicated the cell nuclei.

The enhancement in binding and capture capability of functionalized dendrimers was attributed to the increased amounts of antibody onto dendrimer surface, the dendrimer-mediated multivalent binding effects [24], the double specificity to the EpCAM and Slex-expressing colon cancer cells [42-45] through dual antigen-antibody interactions and the enhanced local topographic interactions between modified dendrimers and nanoscale cell surface $[26,46,47]$. These results confirmed us of the possibility that coupling dual antibodies aEpCAM and aSlex onto G6 PAMAM dendrimers would facilitate the accomplishment of multivalent binding and multi-targeting effects, which showed the great potential for increased detection selectivity and specificity of CTCs in patient blood.

\subsection{Down-regulation of the viability of captured cells}

Cell viability induced by G6-5A-5S conjugate was firstly studied. The investigated cell lines include HELF, A-375, Hela, HepG2 and HT29. These cell lines usually express different levels of EpCAM and Slex [29, 42-45]. Fig. 3a showed that G6-5A-5S conjugate had discrepant anti-proliferation effects on the different cell lines in a concentration-dependent manner. Moreover, relatively stronger inhibition effect was found on HT29 cells as compared to other cell lines, which might be attributed to the higher expression level of EpCAM and Slex on HT29 cells [29, 42-45]. However, G6-5A-5S conjugate at the concentration up to $20 \mu \mathrm{g} / \mathrm{mL}$ only led to the reduced cell viability of $41.7 \%$. Colon cancer has the relatively medium risk of cancer recurrence and metastasis [48-51], we thus regard colon cancer cell HT29 as an ideal CTC model [36, 39]. To further determine the regulation abilities of single or dual antibody conjugates G6-5A, G6-5S and G6-5A-5S to capture HT29 cells, similar assay was performed. According to the UV spectra, the molecular weights of G6-5A, G6-5S and G6-5A-5S conjugates were estimated respectively as $377 \mathrm{kDa}, 955 \mathrm{kDa}$ and $1270 \mathrm{kDa}$. At the same mass concentration level, the molar concentration of G6-5A-5S was less than that of G6-5S and G6-5A. CC G6 was even 5-fold molar excess over any other conjugates. Fig.3b showed that G6-5A and G6-5A-5S conjugates decreased the HT29 cell activity with the concentration varying from 5, 10 to $20 \mu \mathrm{g} / \mathrm{mL}$. In contrast, CC G6 and G6-5S conjugate didn't exert the significant effect. This result suggested the importance of aEpCAM conjugated onto dendrimers in the down-regulation of cell activity, which was consistent with the higher expression level of EpCAM than Slex on HT29 surface [43]. Based on the estimated molecular weight, we converted the antibody concentration unit from $\mu \mathrm{g} / \mathrm{mL}$ to $\mathrm{nM}$. We also converted the \% cell viability (Fig. $3 \mathbf{b}$ ) into \% inhibition rate. We then expressed the effects of three conjugates on the HT29 by using \% inhibition rate/ nM. The calculation result (Table 1) clearly indicated the advantage of the dual antibody conjugate (G6-5A-5S) over the single antibody conjugates. 

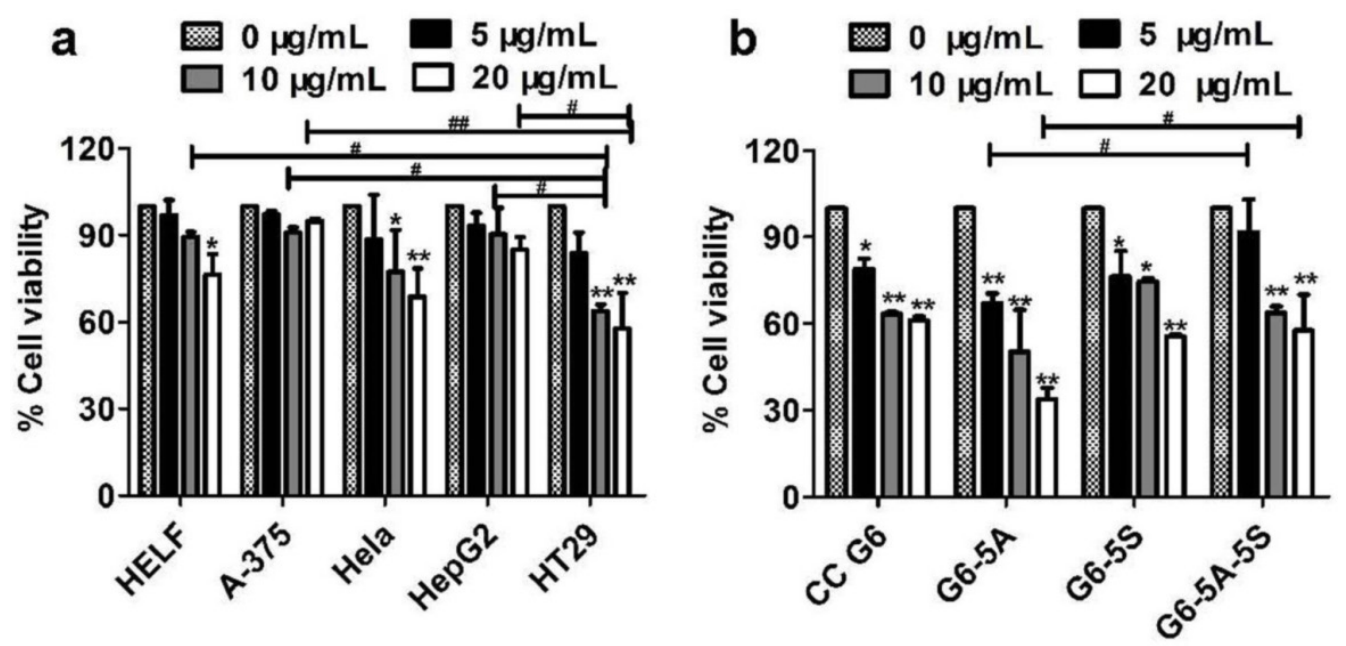

Figure 3. Changes in cell activity after captured by the conjugates. a, Anti-proliferation effects of the dual antibody conjugate G6-5A-5S on various cell lines at different concentrations. b, Comparison in capability between single or dual antibody conjugates in inhibiting HT29 cells. The CC G6 used as the negative control had the 5-6-fold molar excess over other conjugates.

Table I. The mean inhibition rate of the conjugates calculated by dividing their \% inhibition by corresponding molar concentration (nM) converted from the actual concentration unit $\mu \mathrm{g} / \mathrm{mL}$.

\begin{tabular}{llll}
\hline $\begin{array}{l}\text { Concentration } \\
(\mu \mathrm{g} / \mathrm{mL})\end{array}$ & \multicolumn{2}{l}{ Inhibition rate $(\%)$} \\
\cline { 2 - 4 } G6-5A-5S & $2.13 \pm 5.03$ & 10 & 20 \\
G6-5S & $4.48 \pm 2.90 \# \#+0.47 \# \#$ & $2.70 \pm 1.37$ \\
G6-5A & $2.48 \pm 0.45$ & $1.88 \pm 0.95$ & $2.12 \pm 0.07$ \\
CC G6 & $0.29 \pm 0.09$ & $0.26 \pm 0.01$ & $1.25 \pm 0.13$ \\
\hline
\end{tabular}

$\# P<0.05 ; \# \#<<0.01$ compared with CC G6.

Cell cycle distribution was an index of how extraneous materials regulate the cell activity. DNA flow cytometric analysis was used to determine the change in cell population in the phase G0/G1, S and G2/M after treatment. The cell cycle distribution induced by single or dual antibody conjugates at various concentrations $(0,10,20 \mu \mathrm{g} / \mathrm{mL})$ was respectively determined with PI staining. After $48 \mathrm{~h}$ incubation, compared with the untreated control, these conjugates G6-5A, G6-5S and G6-5A-5S could produce a concentration-dependent increase in cell population in the $S$ phase and a reduction in cell population in the G2/M phase without a significant influence on cell population in the G0/G1 phase (Fig. 4b). However, only less than $15 \%$ increase in $S$ phase cell population was observed, which reflected the moderate capability of three conjugates in regulating HT29 activity, and was in agreement with the above MTT results. The effect of dual antibody conjugate G6-5A-5S on the cell cycle distribution was also observed by the flow cytometric image (Fig. 4a). The conjugates that arrested the cellular DNA synthesis in S phase prevented cells from going into G2/M checkpoint earlier, resulting in the down-regulation of the captured cells.
Whether dendrimer-antibody conjugates could induce the HT29 cells into apoptotic and necrotic stages was studied respectively using the qualitative and quantitative analyses. CC G6 was tested as the negative control. Cells incubated with conjugates were exposed to AO/EB dyes in dark for morphological observation. Fluorescence phase-contrast images in Fig. 4c showed that the cells treated with the conjugates at 10 and $20 \mu \mathrm{g} / \mathrm{mL}$ displayed the condensation of chromatin and pycnosis of nucleus without significant membrane blebbing and apoptotic bodies (blue arrow). On the contrary, the untreated controls and treated cells with CC G6 dendrimers both showed the uniform green fluorescence, and the clear cellular structure with the integrity of cytomembrane and organelles (purple arrow). This phenomenon revealed the biosafety of the carboxylated dendrimers. Annexin V-FITC/PI apoptotic analysis was performed to classify cells into four populations: debris (damaged cells, only positive to PI), viable (negative to FITC and PI), apoptotic (only positive to FITC) and necrotic (positive to both FITC and PI) [38]. Compared with control, the percentage of viable cell population was decreased and that of early apoptotic or necrotic population increased in a concentration-dependent manner. However, the maximum percentile was less than $10 \%$ and $20 \%$ respectively in apoptotic and necrotic stage. G6-5A and G6-5A-5S conjugates caused no significant increase in apoptotic stage but about $10 \%$ increase in necrotic stage while G6-5S conjugate resulted in approximately $20 \%$ increase in both early apoptotic and necrotic stage (Fig. 5a). The above results suggested that the conjugates slightly induced cells into early apoptosis without producing a significant cytotoxic effect. 

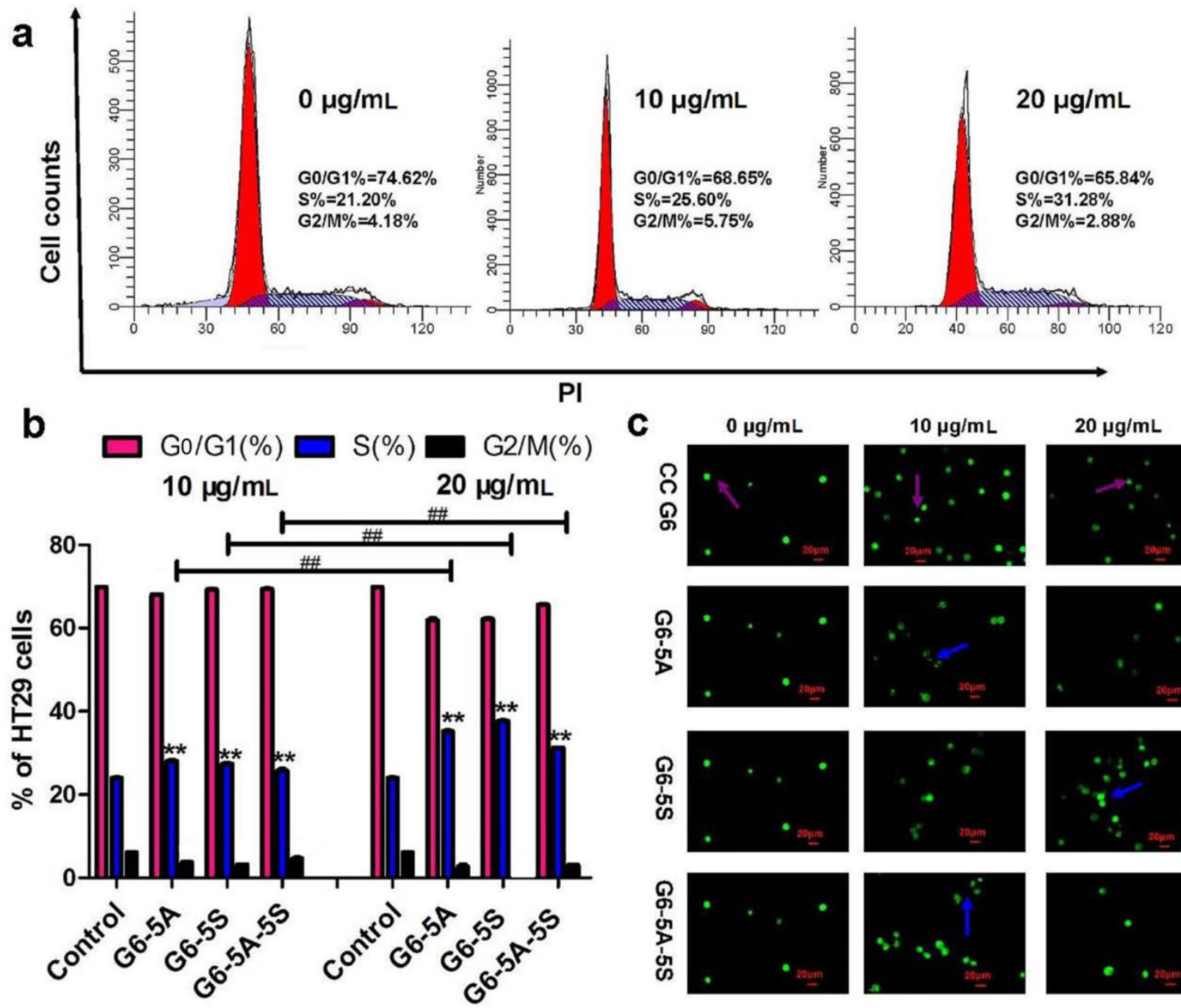

C $\quad 0 \mu \mathrm{g} / \mathrm{mL}$
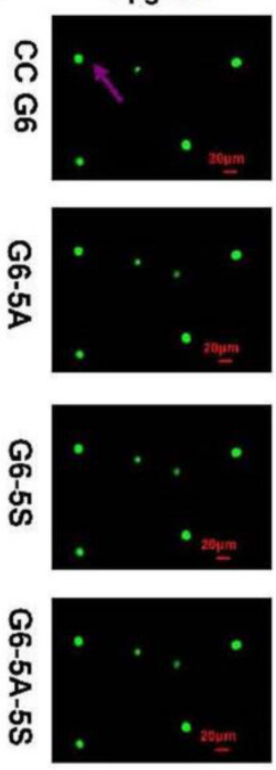

$10 \mu \mathrm{g} / \mathrm{mL}$


$20 \mu \mathrm{g} / \mathrm{mL}$
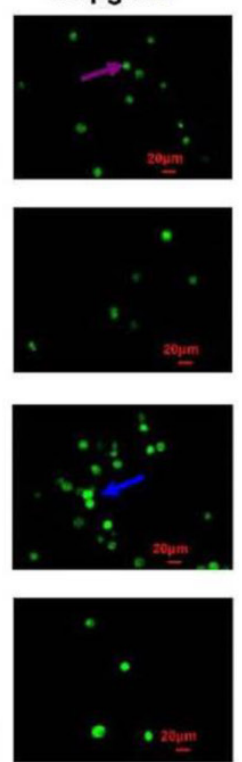

Figure 4. Cell cycle distribution and morphological change induced by the single or dual antibody conjugates ( 10 and $20 \mu g / \mathrm{mL})$. a, Representative flow cytometric images of HT29 cells after incubation with G6-5A-5S conjugate. b, Quantitative analysis of the effects of conjugates on the cell population in the phases of G0/GI, S and G2/M. c, Fluorescence microscopic images of the $\mathrm{HT} 29$ cells treated with conjugates.
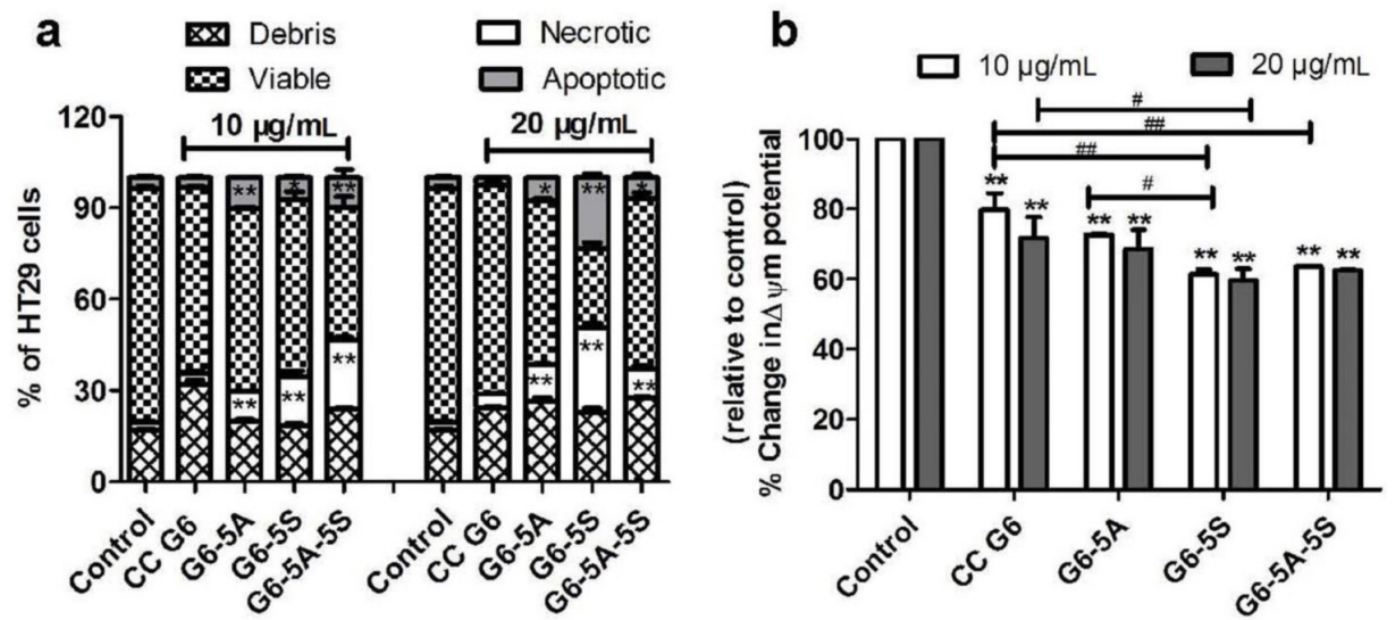

Figure 5. Flow cytometric analyses of the apoptotic status and MMP of HT29 cells caused by the single or dual antibody conjugates with increasing concentrations from 10 to $20 \mu \mathrm{g} / \mathrm{mL}$. a, Analysis of apoptosis of HT29 cells by Annexin-FITC/PI double-labeling. b, Changes of MMP of HT29 cells with DiOC6(3) staining. 
How the conjugates affected the cell apoptosis was further evaluated by analysis of the cellular MMP $(\Delta \psi \mathrm{m})$. The depolarization of MMP usually predicts the starting of apoptosis. With DiOC6(3) staining, untreated cells showed the well-defined integral mitochondrial membrane with normal cristae structure while damaged cells showed the increased membrane permeability as well as the changed cellular $\Delta \psi m$. Flow cytometric analysis displayed that these three conjugates similarly resulted in the decreased cellular MMP in a modest concentration-dependent manner, while CC G6 dendrimers didn't show significant influences. For example, at the same concentration of 20 $\mu \mathrm{g} / \mathrm{mL}, \mathrm{G} 6-5 \mathrm{~S}$ and G6-5A-5S conjugates reduced the cellular $\triangle \psi m$ approximately by $40 \%$ (Fig. 5 b). The changes in cellular MMP confirmed the moderate regulation of dendrimer-antibody conjugates on the cell activity, which was consistent with the above cytotoxicity, cell cycle distribution and cell apoptosis analyses.

It seemed that dendrimers assembling with aEpCAM or/and aSlex exhibited the moderate inhibition effects on the cell activity. The difference in the regulation capability among single or dual antibody conjugates might be related to the amounts and species of antibody onto dendrimer surface, and the multiple interactions between antigen and antibody. Dual antibody-coated dendrimers are superior to single antibody-coated ones in down-regulating the cell activity from the cellular level.

\subsection{Anti-adhesion efficiency}

aSlex may interrupt the hetero-adhesion between cancer cells and endothelial cells through Slex/E-selectin interaction; aEpCAM may directly decrease the adhesion capability of cancer cells. The effects of the aEpCAM or/and aSlex-coated dendrimers on the adhesion of cancer cells to endothelial cells were explored here. According to the results of cell activity regulation, concentrations ranging from 1.25 to $10 \mu \mathrm{g} / \mathrm{mL}$ were selected as the effective and safe dosages for the adhesion assay.

The intervention of the conjugates with the adhesion of HT29 cells to Fn-coated artificial substrate membrane was studied. The artificial membrane was usually regarded as extracellular matrix (ECMs). Fig. 6a showed that compared to CC G6 dendrimers, the adherence of HT29 cells to ECMs was concentration-dependently $(1.25$ to $10 \mu \mathrm{g} / \mathrm{mL})$ blocked by the single or dual antibody conjugates. G6-5A conjugate showed stronger anti-adhesion effect on HT29 cells than G6-5S conjugate, probably because of the higher levels of EpCAM than Slex on the cell surface [43]. Moreover, G6-5A-5S conjugate at molar concentrations less than G6-5A and G6-5S displayed a remark- able advantage in interfering the adherence of cancer cells to the ECMs, and its anti-adhesion efficiency reached $67 \%$ at the concentration of $10 \mu \mathrm{g} / \mathrm{mL}$.

Adhesion of CTCs to vascular endothelial cells is a crucial starting point of cancer metastasis. Blocking the hetero-adhesion between tumor cells and endothelial cells may provide an effective way to prevent cancer metastasis. To imitate and evaluate the capability of the conjugates in interfering the adherence of CTCs to vascular endothelial cells, we used human HT29 and HUVECs. Fluorescence analysis revealed that G6-5A, G6-5S and G6-5A-5S inhibited the adherence of Rhodamine 123-labeled HT29 cells to HUVECs in a concentration-dependent manner (Fig. 6b). The numbers of the adhered HT29 cells were decreased with the increasing concentrations of G6-5A-5S conjugate from 2.5, 5 to $10 \mu \mathrm{g} / \mathrm{mL}$ (Fig. 6d). In comparison, the number of the adhered HT29 cells treated with G6-5A-5S conjugate was less than that treated with G6-5A or G6-5S conjugate at the same concentration of $10 \mu \mathrm{g} / \mathrm{mL}$ (Fig. 6c). CC G6 dendrimers, however, didn't produce significant effects. The result suggested that the anti-adhesion effects of dendrimer-antibody conjugates were mainly exerted by targeting antibodies conjugated onto the dendrimers, rather than dendrimers themselves. When the comparison was made between the single and dual antibody conjugates based on their molar concentrations converted from the actual concentrations used in $\mu \mathrm{g} / \mathrm{mL}$ (Table 2), the dual antibody conjugate showed a significant advantage in inhibiting the adhesion of HT29 cells to HUVECs over its single antibody counterparts. The stronger anti-adhesion capability of G6-5A-5S conjugate might be due to the synergetic effect exerted by aEpCAM and aSlex together. The results from the adhesion assay suggested that dendrimers coated with aEpCAM or/and aSlex might play an important role in interrupting the adhesion and invasion process of CTCs to vessel walls. The above observed effect may collectively result from the inhibition by the conjugates on the adhesion between CTCs and HUVECs, as well as cell growth and proliferation.

Table 2. The mean inhibition rate of the conjugates calculated by dividing their \% inhibition on the adhesion of HT29 to HUVECs by corresponding molar concentrations (nM) converted from the actual concentrations used in $\mu \mathrm{g} / \mathrm{mL}$.

\begin{tabular}{lllll}
\hline $\begin{array}{l}\text { Concentration } \\
(\mu \mathrm{g} / \mathrm{mL})\end{array}$ & \multicolumn{5}{l}{ Inhibition rate $(\%)$} \\
\cline { 2 - 5 } & 1.25 & 2.5 & 5 & 10 \\
\hline G6-5A-5S & $26.64 \pm 3.48^{\# \#}$ & $16.12 \pm 2.22^{\# \#}$ & $8.72 \pm 0.58^{\# \#}$ & $6.17 \pm 0.07 \# \#$ \\
G6-5S & $10.85 \pm 4.16^{\# \#}$ & $9.17 \pm 0.91 \# \#$ & $6.74 \pm 0.47 \#$ & $4.26 \pm 0.28$ \\
G6-5A & $4.19 \pm 1.83$ & $3.94 \pm 0.48$ & $2.66 \pm 0.34$ & $1.70 \pm 0.04$ \\
\hline
\end{tabular}

$\# P<0.05 ; \# \#<0.01$ compared with G6-5A conjugate. 


\subsection{Capture efficiency invivo}

After demonstrating that single or dual antibody conjugates could bind the adherent and suspensory HT29 cells in vitro, we wanted to explore whether the rare HT29 cells could be sensitively and specifically captured by the conjugates in vivo. We injected small amount of HT29 cells into the nude mice followed by administration of the conjugates, separately, to the mice. SSC versus PE, or SSC versus FITC histogram, and PE versus FITC plot quadrant showed the specific binding of single and dual antibody conjugates to the HT29 cells, respectively. The in vivo study showed that by $1 \mathrm{~h}$ after the injection with the conjugates, the single or dual antibody conjugates were able to capture the target HT29 cells in blood. Flow cytometric analysis revealed that the number of HT29 cells captured by the dual antibody conjugate within Q2 plot quadrant was more than that by the single antibody conjugates (Fig. 7a). The dynamic capture efficiency of the dual antibody-coated dendrimers PE-5A-G6-5S-FITC was 1.8\% and 2\% higher than that of the single antibody-coated dendrimers G6-5A-PE and G6-5S-FITC (Fig. 7b). The result indicated that the dual antibody conjugate could sensitively and specifically capture the target CTCs model whatever in static in vitro and dynamic in vivo conditions.


C C G6

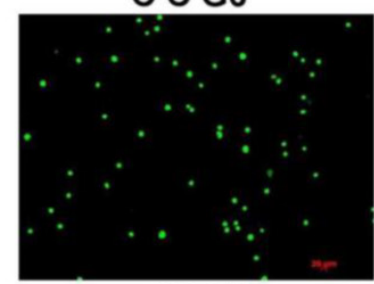

G6-5S

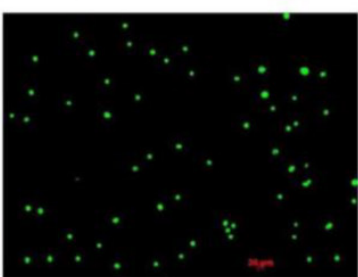

G6-5A

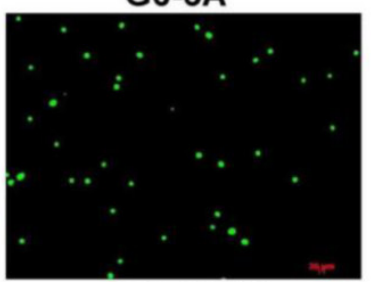

G6-5A-5S

$10 \mu \mathrm{g} / \mathrm{mL}$

b
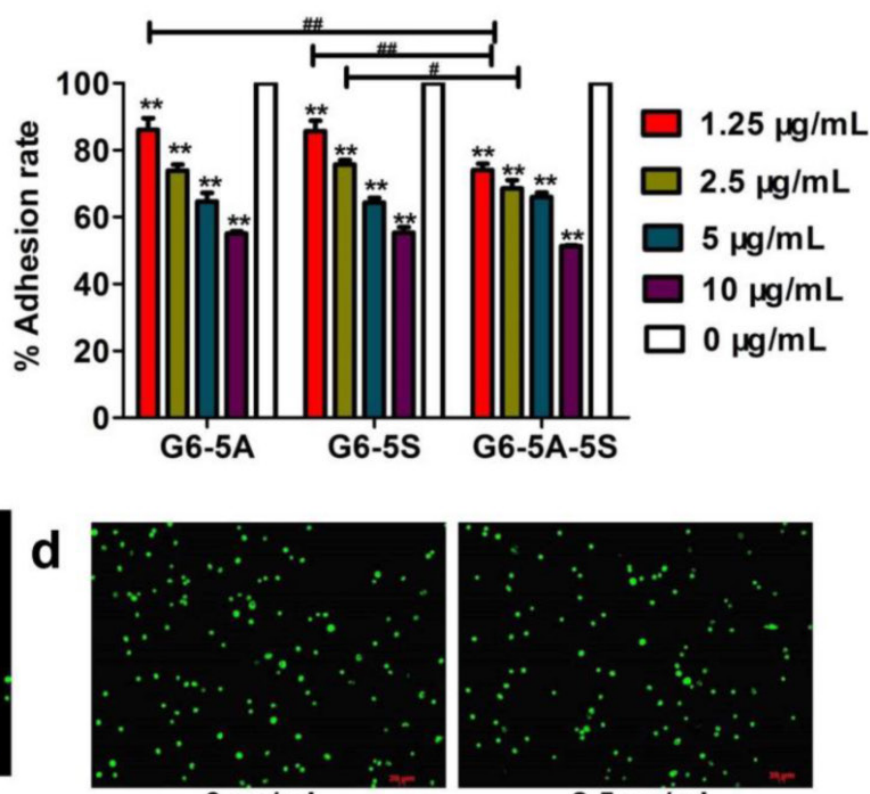

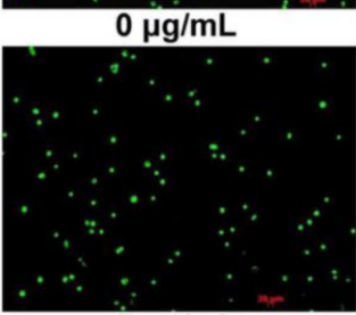

$5 \mu \mathrm{g} / \mathrm{mL}$

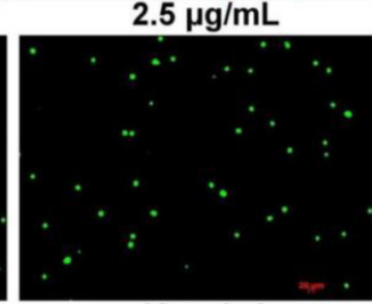

$10 \mu \mathrm{g} / \mathrm{mL}$


G6-5A-5S

Figure 6. Anti-adhesion effects of single or dual antibody conjugates evaluated by MTT and fluorescence microscope methods. a, Inhibition of HT29 cells adhered to Fn-coated substrate by the conjugates at concentrations ranging from 1.25 to $10 \mu \mathrm{g} / \mathrm{mL}$. b, Quantitative analysis of the inhibition by various concentrations of conjugates on the adhesion of HT29 cells to HUVECs. c and d, Representative fluorescence images of Rhodamine 123-labeled HT29 cells adhered to HUVECs treated with the individual conjugates at concentration of $10 \mu \mathrm{g} / \mathrm{mL}$ (left); or with G6-5A-5S conjugate at concentrations ranging from $2.5,5$ to $10 \mu \mathrm{g} / \mathrm{mL}$ (right) . 

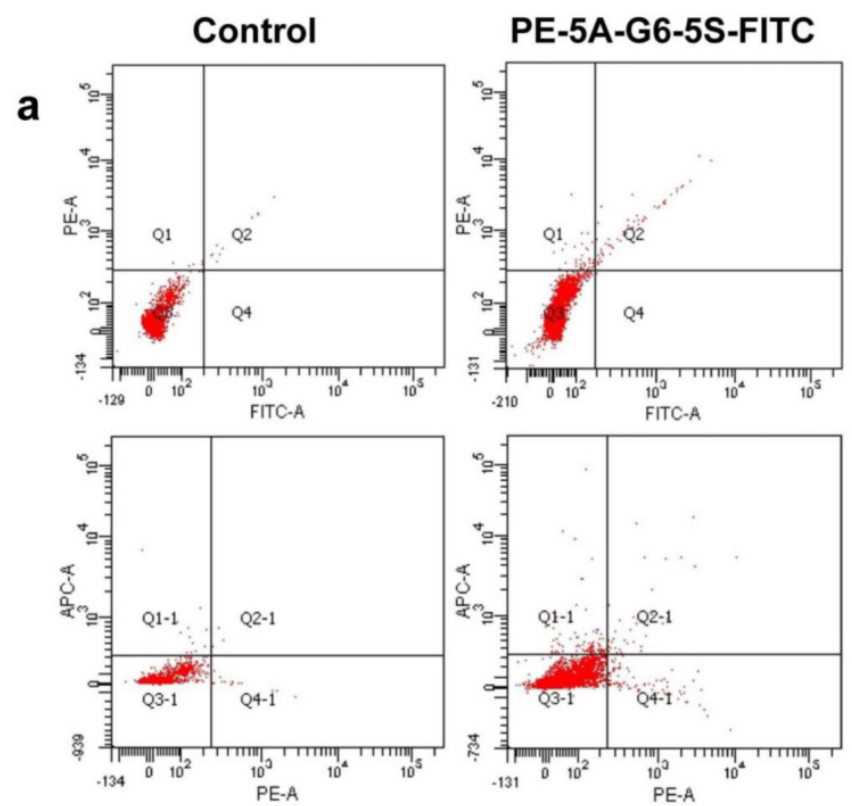

b

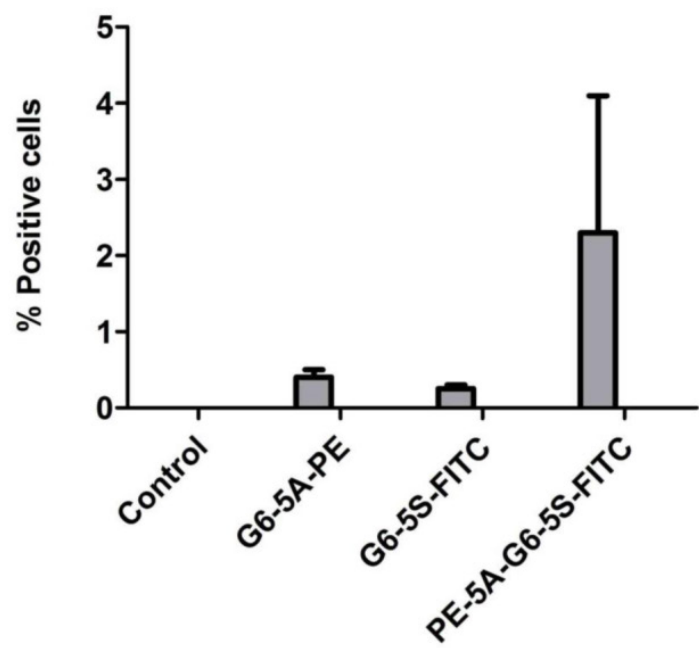

Figure 7. Quantification of the captured HT29 cells after injection to nude mice by flow cytometry. a, Quantitative images of the HT29 cells captured by the dual antibody conjugate. $\mathbf{b}$, Difference in capture efficiency between the single conjugates and dual ones. PE-5A-G6-5S-FITC conjugate captured more circulating HT29 than any single conjugates. The captured efficiency of dual conjugate was five to ten times higher than that of single ones.

\section{Conclusions}

In the present study, we prepared the single or dual antibody conjugates with or without fluorescence labeling. Physiochemical characterization by using UV, AFM, FSEM, DLS, electrophoresis, chromatography and fluorescent measurements demonstrated the successful functionalization. Fluorescence-labeled single or dual antibody conjugates displayed the enhanced recognition and binding capability on the adhesive and floating HT29 cells in comparison with the fluorescence-labeled antibody alone. Moreover, dual antibody-coated dendrimers were superior to any single antibody-coated coun- terparts in capturing HT29 cells. MTT and PI staining measurements showed that the conjugates without fluorescence labeling resulted in a reduction in cell activity by arresting the cell proliferation in $S$ phase. Cell apoptosis and MMP analyses revealed that conjugates could only induce the cells into early apoptotic stage to the maximum extent, and change the cellular MMP in a modest concentration-dependent manner. The decreased cell viability was mainly ascribed to the interruption of EpCAM on HT29 cell surface. MTT and fluorescence photograph analyses displayed the concentration-dependent inhibition of the conjugates on the adherence of HT29 cells to Fn-coated substrates and HUVECs. Besides, the dual antibody-coated dendrimers exhibited the stronger anti-adhesion effects. aEpCAM and aSlex might play the synergetic effects on interfering the hetero-adhesion of HT29 cells to HUVECs rather than dendrimers themselves.

Taken together, the present study not only exhibited the architecture of functionalized dendrimers coated with dual antibodies (aEpCAM and aSlex) but also explored their biological functions. The advances in spatiotemporally coating of PAMAM dendrimers with aEpCAM and aSlex allow us to explore the new initiative for the enhanced control of target HT29 cells and their hetero-adhesion to HUVECs. Our study showed the possibility of preventing cancer metastasis via the blood circulation by blocking the several crucial steps using nanomaterials multivalently conjugated with dual targeting antibodies.

\section{Supplementary Material}

Table S1 and Fig.S1.

http://www.thno.org/v04p1250s1.pdf

\section{Acknowledgments}

The authors are thankful to the East Hospital of Xiamen University for providing the fresh human umbilical cords of new-born babies. This work was supported by grants from the Ministry of Science and Technology of China (2015CB931804), National Science Foundation of China (81273548 and 81201709), the Natural Science Foundation of Fujian Province of China (2014J01364) and the National Health and Family Planning Commission (WKJ-FJ-15).

\section{Conflicts of Interest}

The authors declare no competing financial interest.

\section{References}

[1] Pantel K, Brakenhoff RH. Dissecting the metastatic cascade. Nat Rev Cancer 2004;4:448-56.

[2] Steeg PS. Tumor metastasis: mechanistic insights and clinical challenges. Nat Med 2006:12:895-904

[3] Klein CA. Cancer. The metastasis cascade. Science 2008;321:1785-7. 
[4] Wang JC, Chen JZ, Shao JW, Wan LY, Lu YS, Zhu YW, et al. Synthesis, spectral characterization and in vitro cellular activities of metapristone, a potential cancer metastatic chemopreventive agent derived from mifepristone (RU486). The AAPS Journal 2013.

[5] Dotan E, Cohen SJ, Alpaugh KR, Meropol NJ. Circulating tumor cells: evolving evidence and future challenges. Oncologist 2009;14:1070-82.

[6] Pantel K, Alix-Panabieres C, Riethdorf S. Cancer micrometastases. Nat Rev Clin Oncol 2009;6:339-51.

[7] Yu M, Stott S, Toner M, Maheswaran S, Haber DA. Circulating tumor cells: approaches to isolation and characterization. J Cell Biol 2011;192:373-82.

[8] Meng S, Tripathy D, Frenkel EP, Shete S, Naftalis EZ, Huth JF, et al. Circulating tumor cells in patients with breast cancer dormancy. Clin Cancer Res 2004;10:8152-62.

[9] Naumov GN, MacDonald IC, Chambers AF, Groom AC. Solitary cancer cells as a possible source of tumour dormancy? Semin Cancer Biol 2001;11:271-6.

[10] Plaks V, Koopman CD, Werb Z. Cancer. Circulating tumor cells. Science 2013;341:1186-8.

[11] Chaffer CL, Weinberg RA. A perspective on cancer cell metastasis. Science 2011;331:1559-64.

[12] Gao Y, Xie J, Chen H, Gu S, Zhao R, Shao J, et al. Nanotechnology-based intelligent drug design for cancer metastasis treatment. Biotechnol Adv 2013.

[13] Jia L, Lu Y, Shao J, Liang X-J, Xu Y. Nanoproteomics: a new sprout from emerging links between nanotechnology and proteomics. Trends Biotechnol 2012.

[14] Desgrosellier JS, Cheresh DA. Integrins in cancer: biological implications and therapeutic opportunities. Nat Rev Cancer 2010;10:9-22.

[15] Krivacic RT, Ladanyi A, Curry DN, Hsieh HB, Kuhn P, Bergsrud DE, et al. A rare-cell detector for cancer. Proc Natl Acad Sci U S A 2004;101:10501-4.

[16] Zieglschmid V, Hollmann C, Bocher O. Detection of disseminated tumor cells in peripheral blood. Crit Rev Clin Lab Sci 2005;42:155-96.

[17] Sieuwerts AM, Kraan J, Bolt-de Vries J, van der Spoel P, Mostert B, Martens $\mathrm{JW}$, et al. Molecular characterization of circulating tumor cells in large quantities of contaminating leukocytes by a multiplex real-time PCR. Breast Cancer Res Treat 2009;118:455-68.

[18] Pantel K, Otte M. Occult micrometastasis: enrichment, identification and characterization of single disseminated tumour cells. Semin Cancer Biol 2001;11:327-37.

[19] Allard WJ, Matera J, Miller MC, Repollet M, Connelly MC, Rao C, et al. Tumor cells circulate in the peripheral blood of all major carcinomas but not in healthy subjects or patients with nonmalignant diseases. Clin Cancer Res 2004; 10:6897-904.

[20] Ozkumur E, Shah AM, Ciciliano JC, Emmink BL, Miyamoto DT, Brachtel E, et al. Inertial focusing for tumor antigen-dependent and -independent sorting of rare circulating tumor cells. Sci Transl Med 2013;5:179ra47.

[21] Schiro PG, Zhao M, Kuo JS, Koehler KM, Sabath DE, Chiu DT. Sensitive and high-throughput isolation of rare cells from peripheral blood with ensemble-decision aliquot ranking. Angew Chem Int Ed Engl 2012;51:4618-22.

[22] Xu Y, Phillips JA, Yan J, Li Q, Fan ZH, Tan W. Aptamer-based microfluidic device for enrichment, sorting, and detection of multiple cancer cells. Anal Chem 2009;81:7436-42.

[23] Sheng W, Chen T, Kamath R, Xiong X, Tan W, Fan ZH. Aptamer-enabled efficient isolation of cancer cells from whole blood using a microfluidic device. Anal Chem 2012;84:4199-206.

[24] Myung JH, Gajjar KA, Saric J, Eddington DT, Hong S. Dendrimer-mediated multivalent binding for the enhanced capture of tumor cells. Angew Chem Int Ed Engl 2011;50:11769-72.

[25] Wang S, Wang H, Jiao J, Chen KJ, Owens GE, Kamei K, et al. Three-dimensional nanostructured substrates toward efficient capture of circulating tumor cells. Angew Chem Int Ed Engl 2009;48:8970-3.

[26] Sheng W, Chen T, Tan W, Fan ZH. Multivalent DNA nanospheres for enhanced capture of cancer cells in microfluidic devices. ACS Nano 2013;7:7067-76.

[27] Huang YF, Chang HT, Tan W. Cancer cell targeting using multiple aptamers conjugated on nanorods. Anal Chem 2008;80:567-72.

[28] Pavlov V, Xiao Y, Shlyahovsky B, Willner I. Aptamer-functionalized Au nanoparticles for the amplified optical detection of thrombin. J Am Chem Soc 2004;126:11768-9.

[29] Haier J, Nasralla M, Nicolson GL. Cell surface molecules and their prognostic values in assessing colorectal carcinomas. Ann Surg 2000;231:11-24.

[30] Veveris-Lowe TL, Lawrence MG, Collard RL, Bui L, Herington AC, Nicol DL, et al. Kallikrein 4 (hK4) and prostate-specific antigen (PSA) are associated with the loss of E-cadherin and an epithelial-mesenchymal transition (EMT)-like effect in prostate cancer cells. Endocr Relat Cancer 2005;12:631-43.

[31] Engering A, Kuhn L, Fluitsma D, Hoefsmit E, Pieters J. Differential post-translational modification of CD63 molecules during maturation of human dendritic cells. Eur J Biochem 2003;270:2412-20.

[32] Baccelli I, Schneeweiss A, Riethdorf S, Stenzinger A, Schillert A, Vogel V, et al. Identification of a population of blood circulating tumor cells from breast cancer patients that initiates metastasis in a xenograft assay. Nat Biotechnol 2013;31:539-44.

[33] Balzar M, Winter MJ, de Boer CJ, Litvinov SV. The biology of the 17-1A antigen (Ep-CAM). J Mol Med (Berl) 1999;77:699-712.

[34] Matsushita Y, Hoff S, Nudelman E, Otaka M, Hakomori S, Ota D, et al. Metastatic behavior and cell surface properties of HT-29 human colon carcinoma variant cells selected for their differential expression of sialyl-dimeric Lex antigen. Clin Exp Metastas 1991;9:283-99.

[35] Jaffe EA, Nachman RL, Becker CG, Minick CR. Culture of human endothelial cells derived from umbilical veins. Identification by morphologic and immunologic criteria. J Clin Invest 1973;52:2745-56.

[36] Lu Y, Yu T, Liang H, Wang J, Xie J, Shao J, et al. Nitric oxide inhibits hetero-adhesion of cancer cells to endothelial cells: restraining circulating tumor cells from initiating metastatic cascade. Sci Rep 2014;4:4344.

[37] Shao J, Xue J, Dai Y, Liu H, Chen N, Jia L, et al. Inhibition of human hepatocellular carcinoma HepG2 by phthalocyanine photosensitiser PHOTOCYANINE: ROS production, apoptosis, cell cycle arrest. Eur J Cancer 2012;48:2086-96

[38] Shao J, Dai Y, Zhao W, Xie J, Xue J, Ye J, et al. Intracellular distribution and mechanisms of actions of photosensitizer Zinc(II)-phthalocyanine solubilized in Cremophor EL against human hepatocellular carcinoma HepG2 cells. Cancer Lett 2013;330:49-56.

[39] Wang J, Chen J, Wan L, Shao J, Lu Y, Zhu Y, et al. Synthesis, spectral characterization, and in vitro cellular activities of metapristone, a potential cancer metastatic chemopreventive agent derived from mifepristone (RU486). AAPS J 2014;16:289-98

[40] Islam MT, Shi X, Balogh L, Baker JR, Jr. HPLC separation of different generations of poly(amidoamine) dendrimers modified with various terminal groups. Anal Chem 2005;77:2063-70.

[41] Wang D, Imae T. Fluorescence emission from dendrimers and its $\mathrm{pH}$ dependence. J Am Chem Soc 2004;126:13204-5.

[42] Went PT, Lugli A, Meier S, Bundi M, Mirlacher M, Sauter G, et al. Frequent EpCam protein expression in human carcinomas. Hum Pathol 2004;35:122-8.

[43] Belov L, Zhou J, Christopherson RI. Cell surface markers in colorectal cancer prognosis. Int J Mol Sci 2010;12:78-113.

[44] Nakamori S, Kameyama M, Imaoka S, Furukawa H, Ishikawa O, Sasaki Y, et al. Increased expression of sialyl Lewisx antigen correlates with poor survival in patients with colorectal carcinoma: clinicopathological and immunohistochemical study. Cancer Res 1993;53:3632-7.

[45] Fujita T, Murayama K, Hanamura T, Okada T, Ito T, Harada M, et al. CSLEX (Sialyl Lewis X) is a useful tumor marker for monitoring of breast cancer patients. Jpn J Clin Oncol 2011;41:394-9.

[46] Chen W, Weng S, Zhang F, Allen S, Li X, Bao L, et al. Nanoroughened surfaces for efficient capture of circulating tumor cells without using capture antibodies. ACS Nano 2013;7:566-75.

[47] Wang S, Liu K, Liu J, Yu ZT, Xu X, Zhao L, et al. Highly efficient capture of circulating tumor cells by using nanostructured silicon substrates with integrated chaotic micromixers. Angew Chem Int Ed Engl 2011;50:3084-8.

[48] Greenberg D, Earle C, Fang CH, Eldar-Lissai A, Neumann PJ. When is cancer care cost-effective? A systematic overview of cost-utility analyses in oncology. J Natl Cancer Inst 2010;102:82-8.

[49] Tamoxifen for early breast cancer: an overview of the randomised trials. Early Breast Cancer Trialists' Collaborative Group. Lancet 1998;351:1451-67.

[50] Sargent DJ, Patiyil S, Yothers G, Haller DG, Gray R, Benedetti J, et al. End points for colon cancer adjuvant trials: observations and recommendations based on individual patient data from 20,898 patients enrolled onto 18 randomized trials from the ACCENT Group. J Clin Oncol 2007;25:4569-74.

[51] Hanahan D, Weinberg RA. Hallmarks of cancer: the next generation. Cell 2011;144:646-74. 